\title{
Solutions to the Problems Concerning Descartes' Interactionism
}

\author{
Md. Ezazul Karim ${ }^{1}$ \\ ${ }^{1}$ Graduate student of philosophy from University of Oklahoma, USA \\ Correspondence: Md. Ezazul Karim, Graduate student of philosophy from University of Oklahoma, USA.
}

Received: April 10, 2020

Accepted: May 4, $2020 \quad$ Available online: May 20, 2020

doi:10.11114/ijsss.v8i4.4866

URL: https://doi.org/10.11114/ijsss.v8i4.4866

\begin{abstract}
Philosophy of mind in its essence philosophizes about the mind. And among many questions that it raises, the question regarding the relation between the body and the mind is of paramount importance. Among various theories considering the relation between the body and the mind, interactionism shines brightly. Advocated by the philosopher Rene Descartes it is one of the oldest and the most talked about theories. The aim of this paper is to propose some solutions to the problems concerning Rene Descartes' interactionism. In order to do that at first interactionism is going to be discussed. Then the main points concerning Descartes' interactionism along with the initial problems will be discussed. And finally, the solution to these problems will be proposed.
\end{abstract}

Keywords: Interactionism, body, mind, pineal gland, monist, neutral

\section{Introduction}

Rene Descartes' advocated interactionism. Interactionism is the theory regarding the relation between the body and the mind where it is argued that the mental events can cause bodily events, and bodily events can also cause mental events. In his version of interactionism, he argues for the diametrically opposite body and the mind which are themselves substances, interacting with each other via the pineal gland, located within the brain. His claims, nevertheless are not without their own flaws. But these problems are not unsolvable. And this can be done by disregarding the body and the mind from its status of substance and also disregarding the importance of the pineal gland along with holding that the body and the mind come from and are grounded upon the same source which is neutral and monistic; thus allowing them to interact with each other.

\section{Interactionism}

Interactionism is a view regarding the philosophy of mind. It is concerned with the relation between the body and the mind. According to interactionism the body and the mind can interact. This means that they can affect each other. So they can have a causal relation.

This view holds that the body can cause mental events, and the mind can also cause the bodily events. The body can cause mental events. Thus it holds that "states of consciousness can be causally affected by states of body and states of the body can be causally affected by states of consciousness." (Shaffer, 1997, p. 61) For example, falling down can make someone sad. Here falling down is a bodily even and being sad is a mental event which is caused by the body. And the mind can cause the bodily events as well. For example, being sad can make one cry. Here being sad is a mental event which can give rise to crying which is a bodily event. And which is also caused by the mind. So the body can cause mental events, and the mind can also cause the bodily events. In turn, the mental events can be the effect of the bodily process, and the bodily events can also be the effect of the mental process. The mental events can be the effect of the bodily process. For example, being sad is the effect of falling down. Here being sad is the mental event which is the effect of falling down which is the bodily event. And the bodily events can be the effect of the mental process as well. For example, crying is the effect of being sad. Here crying is the bodily event which is the effect of being sad which is the mental process. Thus the mental events can be the effect of the bodily process, and the bodily events can also be the effect of the mental process.

Besides this, some of the bodily events can be the effect of the body, and some of the mental events can be the effect of the mind. The body can also be the cause of some bodily events. For example, falling down can cause internal bleeding. Here falling down is a bodily event that can give rise to internal bleeding which is another bodily event. And the mind can also be the cause of some mental events. For example, remembering something can make one happy. Here 
remembering is a mental event which gives rise to feeling happy which is another mental event. So it can be said that some of the bodily events can be the effect of the body. And some of the mental events can be the effect of the mind.

\section{Descartes' Interactionism and the Problems Concerning It}

Rene Descartes is an advocate of interactionism. He thinks that the body can affect the mind and the mind can affect the body as well. In other words, the body can cause mental events. And the mind can cause bodily events. But there are various problems concerning the interactionism of Descartes. So the main points regarding Descartes' interactionism and the problems concerning them are; the body and the mind are both held as substances but this is problematic as it is illogical that they can interact. It is held that the body and the mind are completely different and this makes their interaction problematic. It is stated that the body is in space and time and the mind is only in time but this is problematic as it makes the existence of mind questionable and their interaction more challenging. Descartes' claim of the body and the mind interacting via the pineal gland is problematic as well.

The body and the mind are both held as substances but this is problematic as it is illogical that they can interact. Descartes thinks that God is the primary substance or say "substance in the absolute sense" (Thilly, 1958, p. 308). Who is independent and every other substance depend on Him. And talking of other substances Descartes gives us the body and the mind. Both of them are substances which depend on the primary substance which is God. Thus they are secondary substances or "relative substances" (Thilly, 1958, p. 308) depending on God. In the case of the problem of the body and mind and their interaction, Descartes talks about "substance dualism." (Copleston, 1964, p. 27) This is also "labeled as Cartesian dualism." (Heil, 2004, p. 16) He says that the body and the mind are "substance of a different kind." (Heil, 2004, p. 16) But yet they can interact. But his conception is beset with problems. The reason being, by definition substance, is self-dependent. Thus they "do not need others to help to exist" (Thilly, 1958, p. 307) let alone interacting with others. And because they do not need others assistance. Thus the possibility of interaction becomes illogical as well. So the body and the mind are both held as substances but this is problematic as it is illogical that they can interact.

It is held that the body and the mind are completely different and this makes their interaction problematic. He thinks that the "mind is completely different from the body." (Robinson, 1998, p. 41) Thus "they are diametrically opposite." (Thilly, 1958, p. 309) He thinks that "the attribute of body is extension, and the attribute of the mind is thinking." (Thilly, 1958, p. 309) And thought can be employed with everything that is "labeled as consciousness." (Thilly, 1958, p. 310) Besides this whereas "body is divisible, mind is indivisible." (Cooney, 2000, p. 23) But here arises a problem. Because, if they are completely different from each other then, how can they interact? So the body and the mind being completely different, makes their interaction problematic.

It is stated that the body is in space and time and the mind is only in time, but this is problematic as it makes the existence of mind questionable and their interaction more challenging. It is stated by Descartes that the body resides in both the space and the time. So "it is spatial" (Hail, 2004, p. 18) and temporal. But the mind only resides in time. Thus it is "non-spatial." (Hail, 2004, p. 17) Now, this is problematic to a lot of people. Because, if the mind is only in time rather than being both in the space and the time. Then how can it interact with the body which is in both the space and the time? How can there be an interaction between things which does not reside in the same space? Or say reside in the same dimension? As space is a dimension and time is another. Besides this, how can we be sure of the existence of mind when it is not in space and we cannot empirically verify it? Therefore, it is stated that the body is in space and time and the mind is only in time but this is problematic as it makes the existence of mind questionable and their interaction more challenging.

Descartes' claim concerning the pineal gland is problematic as well. He thinks that the pineal gland in the medium by which the body and the mind interact. As he states "relation of mind and body is clearly conceived as causal through the mediation of the pineal gland." (Thilly, 1958, p. 311) But it is problematic. The reason being it is unscientific as there could be nothing found within it that ensures the interaction. Besides this Descartes thinks that the pineal gland is the primary seat of the soul. Which means that the soul mainly resides within it. As he says that "the soul though united with the whole body has its principal set in the pineal gland of the brain." (Thilly, 1958, p. 311) But again this is problematic. The reason being unscientific, and lack of convincing evidence. So Descartes' claim concerning the pineal gland is problematic.

\section{Solution to These Problems}

The problems that the Cartesian dualism faces are significant. And they require an equal amount of effort to come up with their solution. And these solutions are; the body and the mind should not be considered as substances. The mind exists but in different dimension or dimensions. There has to be something other than pineal gland to signify this interaction. To interact, the body and the mind must come from the same source- the same substance. This source must be neutral. Besides this, the thing that the body and the mind are grounded upon has to be one or say monistic. And as 
they are grounded upon the same thing so they can interact. The body and the mind must come from and be grounded upon the same source which needs to be neutral and one; allowing them to interact with each other.

The body and the mind should not be considered as substances. This is because substances cannot interact. So to ensure the interaction between the body and the mind, they should be stripped off from the position of being substances. And if they are not substances then it will open the door to the possibility of interaction. So body and the mind should not be considered as substances.

The mind exists but in different dimension or dimensions. Normally we talk about the $3^{\text {rd }}$ which is the width, length, and height. And all these three make up our space. And there is another dimension which is called the $4^{\text {th }}$ dimension which is time. In Descartes' account, the body occupies both of these four dimensions. Where the mind only occupies the 4th dimension which is time. But it can be argued that there are various other dimensions as well. The number of the exact dimensions and their characteristics are debatable. But it does not mean that there are no other dimensions apart from the $1^{\text {st }}, 2^{\text {nd }}, 3^{\text {rd }}$ and $4^{\text {th }}$ dimension. Let alone things that exist within those dimensions. This is because something to be within a dimension implies having existence. For example, if $\mathrm{X}$ is a thing in the $5^{\text {th }}$ dimension, it implies that it exists as it is within a dimension. But it does not necessarily have to occupy other dimensions. Similarly, the mind not being within the $3 \mathrm{~d}$ that is to say within the dimension of space does not restrict itself from existence. This is because in Descartes account the mind is in $4^{\text {th }}$ dimension which is the dimension known as time. But it can be also argued that it is possible that it occupies more than just the $4^{\text {th }}$ dimension that is to say the $5^{\text {th }}$ or the $6^{\text {th }}$ dimensions and so on. And as it occupies at least one dimension which is the 4th dimension, namely time- thus mind exists because occupying any dimension can be asserted as the existence of the thing. So the mind exists but in different dimension or dimensions.

There has to be something other than pineal gland to signify this interaction. This is because the pineal gland fails to certify itself as the primary seat of the soul. This is because by analyzing the pineal gland we find nothing that can be established as the primary seat of the soul. And the same goes for the interaction between the body and the mind via the medium of the pineal gland. So we need something other than pineal gland to signify this interaction.

To interact, the body and the mind must come from the same source- the same substance. This is because the same source can provide a common ground. But different sources cannot provide a common ground. For example, if there is a substance; A having $\mathrm{X}$ as its quality and there is another substance; B having $\mathrm{Y}$ as its quality then, they will not have any common ground. So whatever comes from them may not interact. Thus to have interaction, things need common ground within them. And because of that if the body and the mind are from different sources then they will have no common ground to interact. That is why we need something upon which the mind and also the body is grounded upon. And by which they can interact. So the body and the mind must come from the same source in order to interact.

This source must be neutral. The source has to be neutral as from it these two entities; the body and the mind come from and is grounded upon. Otherwise, if this source would have been only material rather than being neutral, then only the body which is made up of matter would be grounded upon it, not the mind. And on the other hand, if this source was only been ideal or immaterial rather than being neutral, then only the mind would be grounded upon it rather than the body. But as both the body and the mind are grounded upon it then it must be neutral in the question of being material or ideal. So the source has to be neutral.

Besides this, the thing that the body and the mind are grounded upon has to be one or say monistic. Because if it is more than one thing then it is pointless to call it neutral. As if A has the quality of X and B the quality of Y then they are not one thing, thus cannot be neutral. Besides if two things are neutral then it is pointless to say that they are different as well. This is because if A is neutral and B is also neutral then it is pointless to say that they are different. This is because if they have the same quality then they are the same thing. That is why to be neutral it has to be one thing. So the body and the mind are grounded upon one thing, implying, the source is monistic or says one.

And as they are grounded upon the same thing so they can interact. It is true that the body and the mind are different entities. But they can interact as they have common ground. This is because they are grounded upon the same thing which is the neutral monism. So as the body and the mind are grounded upon the same thing so they can interact.

The body and the mind must come from and be grounded upon the same source which needs to be neutral and one; allowing them to interact with each other. The reason being, if there are two substances from which the body and the mind come from and are grounded upon then it will be like this: Substance 1 or S1 having the quality of X, Y and Substance 2 or S2 having the quality of Y, Z. now they clearly have something in common which is the quality Y. But for the body and the mind to arise from this quality Y, it has to be neutral. This is because if it is not neutral then either the body or the mind will arise. Because from material comes body and from ideal comes to mind. But if it is neutral then arises both the body and the mind. And if the $\mathrm{Y}$ is neutral then there can be no $\mathrm{X}$ and $\mathrm{Y}$ in the S1. Similarly, no Y and $\mathrm{Z}$ in S2. This is because if a quality is neutral then it will contain the other quality within it due to being neutral. So there cannot be another quality apart from being neutral if one of the qualities of the substance is neutral. And if that is 
the case then both the S1 and the S2 will have only one quality each; which is neutral. And as both of the qualities are the same- neutral; thus it will be pointless to think that the $\mathrm{S} 1$ and the $\mathrm{S} 2$ are different substances. Thus it makes the- S1 and S2, one and the same substance. Thus ultimately it becomes one substance. And from this one substance, the body and the mind will come and be grounded upon. And because of having the common ground they will be able to interact. Therefore, the body and the mind must come from and be grounded upon the same source which needs to be neutral and one; allowing them to interact with each other.

\section{Conclusion}

To sum up, in the version of interactionism that is advocated and argued by Rene Descartes holds that the diametrically opposite body and the mind that are substances, interacts with each other via the pineal gland that is located within the brain. And although it has its flaws, it can be solved by holding that the body and the mind should not be considered as substances. The mind exists but in different dimension or dimensions. There has to be something other than pineal gland to signify this interaction. To interact, the body and the mind must come from the same source- the same substance. This source must be neutral. Besides this, the thing that the body and the mind are grounded upon has to be one or say monistic. And as they are grounded upon the same thing so they can interact. Along with the fact that the body and the mind must come from and be grounded upon the same source which needs to be neutral and one; allowing them to interact with each other. All by this we can hopefully solve the problem of Descartes' interactionism.

\section{References}

Cooney, B. (2000). The Place of Mind. Belmont: Wadsworth. pp. 23.

Copleston, F. (1964). A History of Philosophy. Vol. 3. New York: Image Books. pp. 21.

Heil, J. (2004). Philosophy of Mind. New York: Routledge. pp. 16-18. https://doi.org/10.4324/9780203506455

Robinson, D. (1998). The mind. Oxford: Oxford University Press. pp. 41.

Shaffer, A. (1997). Philosophy of Mind. New Delhi: Prentice Hall. pp. 16.

Thilly, F. (1958). A History of Philosophy. Allahabad: Central Book Depot. pp. 307-313.

\section{Copyrights}

Copyright for this article is retained by the author(s), with first publication rights granted to the journal.

This is an open-access article distributed under the terms and conditions of the Creative Commons Attribution license which permits unrestricted use, distribution, and reproduction in any medium, provided the original work is properly cited. 